\title{
Алижанова X.A. \\ Профессиональное образование и система требований к экономической подготовке специалиста педагогического профиля
}

Дагестанский государственный педагогический университет (Россия, Республика Дагестан, Махачкала)

doi 10.18411/spc-04-04-2018-02

idsp 000001:spc-04-04-2018-02

В условиях рыночных отношений, с появлением конкуренции, оперативное решение жизненно важных тактических вопросов требует быстрого и экономически оправданного принятия решений, обосновать которые способны только высококвалифицированные специалисты соответствующих областей. Организационная деятельность работников, занятых в сфере управления, включая сотрудников министерств и отделов народного образования, директоров школ, завучей и т.д., должна ориентироваться на использование информационных технологий, позволяющих в короткое время получать важные для учреждения показатели его деятельности. Новые подходы в реализации управленческих функций требуют радикального изменения самой технологии управления, внедрения технических средств преобразования информации, среди которых важнейшее место занимают персональные компьютеры.

Сегодня в новых условиях велика потребность в специалистах, владеющих инструментом проведения анализа, оценки состояния хозяйственной деятельности учреждения, способных намечать и проводить в жизнь мероприятия, изменяющие те или иные показатели в благоприятную сторону. Совершенно ясно, что без применения компьютерных технологий обеспечить такой режим управления очень сложно.

В этой связи чрезвычайную важность приобретают проблемы обучения в области информационных технологий. Развитие этой области человеческих знаний и деятельности протекает столь стремительно, что требует постоянных усилий и совершенствования всех потребителей этих знаний.

Образовательная система должна ответить на эти изменения не столько массовым открытием специализированных академий, институтов (что наблюдается в настоящее время в основном в коммерческой форме обучения), сколько заботой о качестве подготовки специалистов педагогического профиля, о содержании образования в целом и каждой дисциплины в отдельности. Проблемы подготовки специалистов в высшей школе становятся все более актуальными и в связи с ситуацией в стране, и в связи с возрастающими масштабами их выпуска. Перед высшей школой сегодня особенно остро стоят проблемы определения как содержания обучения, отвечающего выдвигаемым обществом задачам, так и организации учебного процесса, выбору форм, методов обучения и подготовки специалистов, отвечающих требованиям времени.

Содержание высшего образования представляет собой педагогическую интерпретацию социального заказа и в идеале должно являться эквивалентом модели будущей профессиональной деятельности. Требования к содержанию обучения в высшей школе определяются государственной стратегией развития высшего образования и отражены в ФГОС ВО.

Сегодня, как отмечает Ю.Г. Татур, ..."во весь рост встает проблема опережающего роста профессиональной компетенции кадров", для решения которой необходимо ..."сместить акцент в обучении с усвоения "готовых знаний" на развитие нестандартного мышления, творческих способностей и качеств», ... «перейти от репродуктивного к творчески-продуктивному типу обучения, призванному обеспечить ...«рывок в повышении качества подготовки специалиста" (там же). Очевидно, что эта проблема отражена в государственном заказе высшей школе. 
В определении содержания подготовки специалиста педагогического профиля важно помнить то, что в настоящее время бурно развивается информатизация общества, средства ее автоматизации. Специалист-педагог, не владеющий современными информационными технологиями подготовки и обработки информации, не сможет реализовать свой профессиональный потенциал. Обучение компьютерным технологиям, осуществляемое в аудиториях, оснащенных современной компьютерной техникой, должно быть направлено, прежде всего, на реализацию целей профессиональной подготовки специалиста. Л. Г. Семушина считает, что именно характер будущей профессиональной деятельности является главным фактором в определении содержания образования. Такой подход позволяет интегрировать формы и методы обучения и разработать программы обучения, отвечающие эффективной подготовке современных специалистов.

Развитие технических и программных средств в последнее время привело к новому взгляду на информатику как учебный предмет. Из дисциплины "модной", она превратилась в мировоззренческую дисциплину, дисциплину, отражающую концепцию всеобщего характера информационных процессов и стала неотъемлемой составляющей содержания высшего образования специалиста. Появившееся понятие "информационные технологии", оказалось столь важным для общественного развития, что практически сразу вошло в название и содержание дисциплины «Информационные технологии».

Применительно к информации, как к ценнейшему общественному ресурсу, технология означает процесс ее переработки (преобразования, отвечающего признакам, характеризующим технологию) для получения информации, обладающей новыми качествами (например, достаточной для аналитических выводов, принятия управленческих решений, получения обобщающих показателей и т.п.). Поэтому по отношению к преобразованию информации стал широко использоваться термин "информационные технологии".

Определения информационной технологии в современных литературных источниках различны, например:

"Информационная технология (ИТ) - это совокупность методов, производственных процессов и программно - технических средств, объединенных в технологическую цепочку, обеспечивающую сбор, обработку, хранение, распространение (транспортировку) и отображение информации с целью снижения трудоемкости процессов использования информационного ресурса, а также повышения их надежности и оперативности".

"Информационная технология - процесс, использующий совокупность средств и методов сбора, обработки и передачи данных (первичной информации) для получения информации нового качества о состоянии объекта, процесса или явления (информационного продукта)" .

Безусловно, изменение названий дисциплин ведет к коренному концептуальному изменению содержания подготовки специалистов в обозначенной области, поиску подходов к соотношению целей и содержания.

Концептуальный характер содержания дисциплины, помимо учета педагогических и организационных принципов, должен базироваться на понимании того, что развитые страны мира и мировое сообщество в целом за последнее десятилетие создали мощную инфраструктуру и высокими темпами осуществляют формирование единого информационного пространства, невхождение в которое России является серьезным препятствием к международному сотрудничеству, ведет к большим экономическим потерям и не позволяет создать в России современный цивилизованный рынок товаров и услуг. 
В поисках новых форм обучения одной из основных проблем теории и практики обучения была и остается проблема отбора содержания обучения, представляющая собой сложную и, несомненно, актуальную проблему.

С целью анализа изменений, сопровождающих вузовскую практику преподавания дисциплин по информационным технологиям, нами выбран метод сравнительного анализа, который применен как для анализа изменения планируемых объемов на изучение дисциплин за выбранный период, так и для анализа изменений содержания дисциплин.

Изменение содержания по «Информатике» трудно выразить в числовом эквиваленте, подобно объемам учебной нагрузки, что дало бы объективную оценку динамики этого изменения. Анализ вариантов программ показывает, что в указанные периоды произошли значительные изменения содержания дисциплин. В большой мере на эти изменения влияет возможность вузов приобретать современную вычислительную технику, позволяющую использовать соответствующее программное обеспечение и удовлетворять через выпускаемого специалиста общественный социальный заказ.

Объективно изменение в содержании этих дисциплин происходит ежегодно в той или иной мере за счет:

- установки новых средств ВТ и программного обеспечения;

- появления новых подходов к обработке информации;

- появления новых информационных технологий;

- поисков и применения новых методов и приемов в обучении;

- включения в содержание лабораторного практикума новых задач по дисциплинам специальности.

Как показал анализ динамики изменений, происходящих в учебных предметах по информационным технологиям, объем знаний и информации, которые должны студенты в настоящее время усваивать, достаточно велики и с каждым годом возрастают, объем же аудиторной учебной нагрузки остается практически неизменным. На это обращают внимание многие исследователи, в частности, И. Е. Вострокнутов видит два пути выхода из этого противоречия "Первый - изменение содержания обучения и перестройка структуры учебных программ в сторону уменьшения учебного материала. Второй - рационализация методов обучения, повышение производительности учебного труда путем внедрения в учебный процесс новых информационных технологий обучения".

В последнее время второй подход к обучению стимулирует творческую активность многих педагогов, исследования которых явили новые подходы к процессам обучения и его осмысления как относительно отдельных дисциплин, так и в вопросах общих проблем подготовки специалистов.

$$
* * *
$$

1. Алижанова Х.А Экономическая подготовка старшеклассников в условиях профильного обучения. Диссертация ... доктора педагогических наук: 13.00.08 / Дагестанский государственный педагогический университет. Махачкала, 2012

2. Алижанова Х.А. Содержание профильной экономической подготовки в национальной системе образования. Вестник Бурятского государственного университета. 2012. № 1-1. с. 133-137

3. Вострокнутов И.Е. Разработка принципов построения моделей оценки эффективности современных информационных технологий учебного назначения. Дисс. канд. пед. наук, СПб.,1995. - 198с.

4. Данилина Й.И. Обучение информатике в условиях профильной дифференциации: (на примере курса экологической направленности). Дисс. канд. пед. наук, Екатеринбург, -1998. - 143с.

5. Семушина Л.Г. Теоретические основы формирования содержания профессионального образования и обучения в средних специальных учебных заведениях. Дисс. док-рапед. наук, М.,1991. 